Sex Roles (2008) 58:535-548 DOI 10.1007/s11199-007-9354-6

\title{
Differences Between and Within Genders in Gender Role Orientation According to Age and Level of Education
}

Antonia Calvo-Salguero \& José Miguel Ángel García-Martínez \& Adelaida Monteoliva

\begin{abstract}
This study analyses the masculinity and femininity in a Spanish simple made upof 164 adult workers (88menand 76 women). To be specific, the objective was to demonstrate whether age and level of education were related to differences in masculinity and femininity, both when comparing between the two genders and when the comparisons are made within the same gender. The results indicated that the two variables predicted differences in women, but not in men. There were only differences between genders in masculinity and femininity between the ages of 20 and 39, and when the level of education is low. The results appear to support Hofstede's hypothesis that there are fewer differences between genders in gender role orientation in feminine countries.
\end{abstract}

Keywords: Gender, Individual differences, Gender role orientation, Age, Level of education, Spain

\section{Introduction}

If one intends to analyse the degree in which men and women adhere to masculine and feminine characteristics, the complex nature of gender role orientation makes it necessary to consider the influence of different variables that make up a human being's existence, such as age and level of education (Auster and Ohm 2000; García-Mina 2002; Twenge 1997b). So, and with regard to age, different theories have expressed that masculinity and femininity are not going to become apparent or be perceived in the same way during one's childhood, adolescence, youth, adulthood or old age (López 1988; Orwoll and Achenbaum 1993; Turner and Turner 1991). Likewise, with regard to level of education, other authors have revealed how people with a high level of education will be less gender-typified, as the university environment has an influence on their beliefs, generating more open, tolerant and egalitarian attitudes and values as regards men and women's family and occupational roles (Brewster and Padavic 2000; Kane 1995; Kulik 2002; Myer and Booth 2002; Togeby 1995; Vedovato and Vaughter 
1980). Despite the above, most research studies that have analysed gender role orientation have been carried out using samples of university students, which prevents the findings from being generalised to other age groups and levels of education (Clekis 2000; Kasen et al. 2006; Twenge 1997b). Furthermore, the fact that much of this research has been developed in the USA means that we have no data from other cultural contexts. With these assumptions in mind, this study uses, as a frame of reference, the theories put forward by Guttman (1975, 1977), Livson (1983) and, Feldman et al. (1981) on the changes in gender role orientation throughout the stages of the life cycle, in order to analyse whether there are differences both between genders and within each gender in masculinity and femininity when age and level of education are considered. In the process of this study, we have carried out univariate and multivariate analyses on a cross-sectional sample of Spanish workers aged between 20 and 64, and two different levels of education (low: basic education, and high: higher education). This analysis will enable the existing empirical void in this matter to be reduced, and will highlight how age and level of education transform a gender's own experience regarding masculinity and femininity, thus helping to understand the highdegree of variability thatmay exist betweenpeoplewho share the same gender and between genders.

\section{Gender, Gender Role Socialisation and Gender Role Orientation}

From the theory of the gender role socialisation, traditionally, it has been assumed that men and women receive different gender role socialisation (Bem 1993; Bonilla 1998; Calvo2002; Konrad et al.2000; Pastor and Martínez-Benlloch 1991; Poal1993; Ritzer 1972; MartinsCrane et al. 1995; Wood and Eagly 2002). So, men undergo a socialisation process whereby they are inculcated that their essential role in life is to be the family's worker and breadwinner, while women are taught that their main role is at the heart of the family, as wife, mother and homemaker. In this way, the practice of the aforementioned roles leads them to specialise in the necessary characteristics and skills to carry out the most significant role for them. Women develop communal or feminine characteristics such as expressing feelings and skills related to caring for others. Men, on the other hand, develop agentic or masculine characteristics that enable them to be successful in the work environment, such as competitiveness and initiative (Echevarría et al. 1992; Konrad et al. 2000; Lorenci-Cioldi 1988; Pastor 1998). So, it is assumed that men would internalise the stereotypes and expectations associated with a masculine gender role socialisation, and that women would internalise those associated with a 
feminine gender role socialisation (Bonilla 1998; Matsumoto 1996; Unger1990). Consequently, from this perspective it has been assumed that men are more masculine than women and that women are more feminine than men.

This assumption has generated that many researchers analysing gender differences in diverse attitudes and behaviour, take gender by itself as an indicator of the degree in which one sharessaid orientations,(e.g.,Duxbury and Higgins 1991; Gutek et al. 1991; Marsden et al. 1993; Vaus and McAllister 1991; Yammarino and Dubinsky 1988), assuming, therefore, that gender and gender role orientation covary (Agut and Salanova 1997) and, that all men and all women are equal (Cinamon and Rich 2002; Kerpelman and Schvaneveldt 1999). However, gender and gender role orientation do not necessarily have to covary (Unger and Crawford 1996; Matsumoto1996). Gender role orientation is a complex component that is based on a gender's reality, but which may not necessarily coincide with that reality, given that socio-cultural and environmental processes play a decisive part in its acquisition and development (Agut and Salanova 1997; Fernández 1988; García-Vega et al. 2005). As will be discussed, several research studies suggest that there may be differences both between genders and within each gender as regards gender role orientation according to the different variables. It is relevant to take these individual differences into account, as otherwise we run the risk of perpetuating gender inequalities, legitimating them in terms of cognitive, and even biological, determinism (Echevarría and Valencia 1993; López 1988).

\section{Differences in Masculinity and Femininity According to Age and Level of Education}

Since the 1970s there has been a series of structural changes, such as the emergence of the feminist movement and the progressive incorporation of women into the labour market, that have brought on the current belief that the traditional gender role socialisation has weakened, creating less internalisation of gender-typified values and attitudes (Moen et al. 1997; Konrad et al.2000). Given these changes, it would be worth considering the existence of individual differences in gender role orientation according to age, as suggested by studies where changes due to the effects of generational cohort have been analysed. On this subject, Twenge (1997b), in a meta-analysis of studies carried out between 1974 and 1995, concludes that masculinity increases in women but femininity does not change. Nevertheless, men do not undergo any change in their 
adherence to feminine and masculine characteristics. Likewise, Spence and Buckner (2000) reached similar conclusions, confirming the hypothesis that social changes have led women to develop more masculine characteristics. Despite the fact that these studies suggest that there are differences in masculinity and femininity according to age, they are somewhat limited. One of the most significant limitations lies in the characteristics of the samples and their cultural origin, as those studies are mainly centred around samples of university students in the USA, so their results may not be generalised to other samples made up of people in other age groups, or with other levels of education, work status and/or from other cultures.

Men and women's self-conception regarding masculinity and femininity reflects historical changes and socio-cultural influences, so we would expect there to be differences in gender role orientation depending on the cultural characteristics of a given country or society. In this way, Hofstede (1998) points out that one of the dimensions where the different cultures may vary is precisely that of masculinityfemininity. In a study analysing data from 53 countries, he identifies the degree of masculinity-femininity that prevails in each one. He found that in masculine countries, men and women were more different (according to traditional gender roles) than in feminine countries, where men and women were more alike (showing characteristics that are traditionally considered feminine). According to the Hofstede (1998) masculinity-femininity index, USA (Score Rank: 15), is a country with a higher level of masculinity than Mediterranean countries such as Spain (Score Rank: 37/38) or Portugal (Score Rank: 45), which tend to be less masculine and, therefore, more relatively feminine countries. To this effect, we would expect the differences in gender role orientation obtained in the aforementioned studies not to be generalisable to Mediterranean countries such as Spain, where, as Hofstede (1998) suggests, there is not a very marked gender categorisation. However, some studies using Spanish university students (García-Vega et al. 2005) have found that the highest percentage of women corresponds to feminine women, and that the highest percentage of men corresponds to masculine men, where the proportion of masculine men is similar to that of feminine women, as Bem (1974) as well as numerous studies from different cultures have also revealed. In other studies using adult samples (Echevarría 1993), the highest percentage of men was found to be masculine and the highest percentage of women corresponds 
equally to the feminine and androgynous types. So the results obtained in Spanish samples do not appear to support the hypothesis put forward by Hofstede (1998).

Furthermore, we would expect to find differences in gender role orientation according to age, due to the effects of developing and maturing throughout the stages of the life cycle. Several theories, such as those proposed by Gutman (1975, 1977), Feldman et al. (1981) or Livson (1983), suggest differences in gender role orientation according to the life experiences, bio-physiological changes and the different family and work roles that are gradually assumed as one develops through the different stages of the life cycle and which are closely related to age. These theories lead to the assumption that, in the early adulthood stage, between the ages of 20 and 30 or 40, approximately, coinciding with the fulfilment of parental roles, an increase comes about in the adherence to the gender roles prescribed by the socialisation process (Gutman 1975, 1977; Feldman et al. 1981). So, women are more feminine and men are more masculine, with changes coming about later on, when these responsibilities are reduced, as the children grow upand leave home, in such away that, midway in to the life cycle, between the ages of 40 and 60 , approximately, men become more feminine and women become more masculine, with both sexes tending towards androgyny. The studies carried out by Helson et al. using samples of female university students born between 1936 and 1939 (Helson and Moane 1987; Helson et al. 2002; Helson and Wink 1992; Roberts et al. 2002; Stewart et al. 2001) suggest that, in women, masculinity tends to be higher in older age groups (for example, between the ages of 43 and 52), which is in accordance with the results given in other studies (Kasen et al. 2006; Parker and Aldwin 1997). However, the results regarding femininity are not that clear. Some studies have found that femininity is higher in younger age groups (between 21 and 27), than in older age groups (e.g. between 27 and 43, and between 43 and 52; Helson and Moane 1987; Helson and Wink 1992). Other studies have found that the level of femininity is higher between the ages of 40 and 50 (Stewart et al. 2001) or between 39 and 59 (Kasen et al. 2006). On the other hand, some studies, in which men have been considered as well as women, show that women adhere more strongly to feminine characteristics and men strongly adhere to masculine characteristics in older age categories (Fischer and Narus 1981; Mandel 1987; Sinnott 1984). 
In short, the results of those studies suggest the existence of differences in masculinity and femininity according to age. However, as occurred with studies that analysed changes in gender role orientation according to the effects of generational cohort, most of those studies use samples from the USA (e.g. Helson et al. 2002; Kasen et al. 2006), and so their results may not necessarily be generalisable to other cultures. Few studies specifically analyse the influence of age on gender role orientation in Spanish samples. However, some studies, such as that carried out by García-Mina (2002), analyse the effects of age on the perception of gender role stereotypes from the assessment of sexually typified social desirability of the 414 personality characteristics that Sandra Bem et al. selected in 1972 in order to draw up the sex role inventory (BSRI). The results of this study indicate that mature adults (average age of 51), as opposed to students (average age of 21), consider fewer characteristics to be more desirable for one gender than another, and that the degree of discrimination of the characteristics selected by the former is lower. Furthermore, López-Zafra and López-Sáez (2001) points out results in the same way. Consequently, as emerges in these studies, students and mature adults differ in their assessment of what is considered stereotypically masculine and feminine in Spanish society. In line with the results obtained in samples from the USA, Spanish adults may display certain gender role stereotypes that are less clearly defined than the younger individuals.

In spite of the fact that it has traditionally been assumed that the differences in masculinity and femininity throughout the life cycle are essentially determined by family roles (Feldman et al. 1981; Gutmann 1975, 1977; Livson 1983), the results from other studies indicate that, at least in the women's case, these differences are more associated with employment status and/or level of education than with family roles (Abele 2003; Cunningham and Antill 1984; Kasen et al. 2006; Roberts1997; McHale and Huston 1984; Vandewater and Stewar 1998). Several authors point out that people with higher education levels are less gender-typified as the university environment has an influence on individual beliefs, generating more open, tolerant and egalitarian values and attitudes towards men and women's work and family roles (Brewster and Padavic 2000; Kane1995; Kulik 2002; Myer and Booth 2002; Togeby 1995; Vedovato and Vaughter 1980). So, from the results of the meta-analysis, Twenge (1997b) concludes that access to higher university education and the increase in working mothers and women working in male-dominated professions are possible change factors that may 
have a bearing on masculine and feminine characteristics. Nevertheless, very few studies have specifically dealt with the extent to which these factors are associated with differences in gender role orientation, basically focusing on samples of women and practically overlooking men altogether. Some indicate that women who have higher education levels and/or are employed have a lower level of femininity than women with a low level of education and/or who do not work; while masculinity increases with higher or university education levels, part or full-time work, with occupational prestige and work in professional positions and/or mainly male-dominated professions (Abele 2000, 2003; Clarey and Stanford 1982; Cunningham and Antill 1984; Holahan and Gilbert 1979; Kasen et al. 2006; Spence and Helmreich 1978; Strange and Ria 1983; Tyer and Erdwins 1979; Twenge 2001).

These studies suggest that there may be differences in masculinity and femininity according to level of education. However, as with age, most studies have been carried out using American samples. Only a few, such as that carried out by Cunningham and Antill (1984) and by Abele (2000, 2003), use samples from other countries (Australia and Germany, respectively). In the Spanish context, there is no existing empirical research into the effect of level of education on gender role orientation. However, we would expect there to be such a relationship, given that in some studies with university students, a higher percentage of androgynous rather than masculine and feminine people has been found (Carvajal et al. 1990; García-Vega et al. 2005).

\section{Objectives and Hypotheses of the Study}

Given the shortage of research into the adherence to gender role orientation in working adults, both men and women, according to age and the level of education, and given the cultural differences that may arise, it would seem necessary to carry out further research dealing with this matter. This is where this project comes in, studying the level of masculinity and femininity in Spain and whose main purpose is to analyse, using a sample of Spanish male and female adult workers, whether there are any individual differences between genders and within each gender with regard to the degree in which they adopt traditional gender role orientations, when age and level of education are considered. On the basis of theories proposed by Guttman $(1975,1977)$, Feldman et al. (1981) and Livson (1983) on the stages of the life cycle, and on the results and suggestions of research that has been carried out on the relationship between age and the 
level of education, the following objectives and hypotheses have been set. This study's first objective was to verify the extent to which men and women adopt traditional gender role orientations. That is, if men adopt a predominantly masculine gender role orientation, and a feminine gender role orientation in the case of women. To this effect, the following hypothesis was set:

\section{Hypothesis 1}

Women will be more feminine than men and men will be more masculine than women.

The second objective was to verify whether there are any differences between and within genders in gender role orientation according to age and level of education. The theories put forward by Guttman (1975, 1977), Feldman et al. (1981) and Livson (1983) propose that the years in which the gender role specialisation is at a maximum, i.e. the years in the life cycle in which men are most masculine and women are most feminine, are produced during the early adulthood stage, around the time of transition from one's twenties to one 's thirties. In the years following the thirties, about midway through the life cycle, between the ages of 40 and 50, approximately, the gender role specialisation becomes weaker, and the differences between genders are reduced, as masculinity rises in women and femininity rises in men. Taking these propositions as a point of reference, the following hypotheses were set:

\section{Hypothesis 2}

There will be differences between genders in masculinity and femininity when both genders are aged between 30 and 39: men will be more masculine and women will be more feminine.

\section{Hypothesis 3}

Women aged between 30 and 39 will be more feminine than women in all the other age groups; likewise, men aged between 30 and 39 will be more masculine than men in all the other age groups.

\section{Hypothesis 4}


Women aged between 50 and 64 will be more masculine than women in all the other age groups; likewise, men aged between 50 and 64 will be more feminine than men in all the other age groups.

Seeing as research suggests that the level of education has an influence on the degree of adherence to gender role characteristics, such that a high level of education favours greater equality between the two genders, the following hypothesis was set:

\section{Hypothesis 5}

There will be differences between genders in masculinity and femininity when the level of education is low: men will be more masculine and women will be more feminine.

\section{Hypothesis 6}

Women with a lower level of education will be more feminine than women with a higher level of education; likewise, men with a lower level of education will be more masculine than those with a higher level of education.

To verify these objectives and hypotheses, across-sectional survey was used, in which both univariate and multivariate analyses were carried out. The results of this study may contribute to generating the belief that gender and gender role orientation do not necessarily have to covary in all situations.

The degree in which each gender adheres to the gender role orientation may be different depending on such important factors as age and levelof education, giving rise to differences both between genders and within each gender. Researchers analysing gender differences in attitudes and behaviour, in order to interpret them in terms of differences in the gender role socialisation process, use gender by itself as an indicator of the degree in which one shares said socialisation,maintaining the belief that all men are more masculine and that all women are more feminine.However,using gender by itself as an indicator of the degree in which one shares the traditional gender role socialisation may lead to bias entering into the interpretation, as not all men, nor all women,are equal.Tothis effect, this study may, on one hand, highlight the need to use indicators in this type of research other than gender by itself, to assess the degree in which one shares the traditional gender role socialisation. One such indicator could be the gender role orientation. Likewise, the results of this study could highlight the value and relevance of 
examining not only the differences between genders, but also the differences within each gender, when xplaining or interpreting the results obtained in terms of the different socialisation processes.Furthermore, it is relevant to take these individual differences into account, as otherwise there could be a risk of attributing gender differences to a cognitive determinism, in the same way that they were attributed to a biological determinism some decades ago (Echevarría and Valencia 1993; López 1988).

\section{Method}

\section{Participants}

The study sample was made up of 137 workers (74 men and 63 women) from two jobs from different occupational levels (teaching staff and janitors or porters) at a Spanish public university. Seeing as the level of education generally tends to correlate with the level of occupation or professional category, these two jobs were selected in order to obtain participants from different educational levels. While the teaching job requires a high level of education, to work as a janitor or porter only requires a minimum or elementary education. All the teachers had reached a university degree level or higher undergraduate course (university graduates and doctors), whereas the janitors or porters had completed primary education or EGB (most basic or elementary level in the Spanish education system). In this way, two groups of participants were formed according to level of education: one for a high level of education (teaching staff) and another for a low level of education (janitors or porters). The teaching staff group was made up of 54 men and 45 women, and the group of janitors or porters was made up of 20 men and 18 women. The participants' age varied between 20 and 64 . The average age of the women was $37.65(\mathrm{SD}=8.447)$ and that of men, $38.18(\mathrm{SD}=8.492)$.

The women's marital status was as follows: 18 single, 34 married, 4 with steady partner and 7 separated, divorced or widowed. The men's marital status was as follows: 13 single, 53 married, 6 with steady partner and 2 separated, divorced or widowed. In the women's group, 30 out of the 63 had children, and in the men's group, 40 out of the 74 . The women's average number of children was $1.158(\mathrm{SD}=1.494)$ and the men's average number of children was 1.13 ( $\mathrm{SD}=1.278)$. All the participants had full-time contracts and worked a normal 40 hour week. 


\section{Variables and Instruments}

The variables considered in this study were: gender, level of education, age and gender role orientation. Variables such as gender, level of education, age and occupational level were compiled in a questionnaire on personal and professional details drawn up for that purpose. Gender was understood as being the person's biological sex. As mentioned in the previous paragraph, two groups of participants were obtained (high and low) with regard to level of education. The low level of education group was made up of participants with the most basic or elementary level within the Spanish education system, and which coincided with those working in the position of janitors or porters, while the high level of education group was made up of participants with higher education (university graduates or doctors) and which coincided with those working as teaching staff. Four age groups were formed: (1) from the age of 20 to 29; (2) from 30 to 39 ; (3) from 40 to 49 and (4) from 50 to 64 . These four groups were established using the different stages of the life cycle put forward by authors such as Gutmann (1975, 1977) and Levinson et al. (1978) as a reference. These theories define an early stage, between the age of 18 and 30 or 40, approximately, which is characterised bystartingwork, formingacouple ormarriage, the birth of children, and other such roles. The rigidity of gender roles is emphasised with the performance of these roles (Guttman 1977; Livson 1983), and the differences and inequalities between men and women become evident. In this period of time, the differences between genders regarding masculinity and femininity are accentuated. In a second stage, between the ages of 40 and 50, approximately, coinciding with a reduction in family responsibilities, children leaving home, more limited professional options, among others, a specialisation or rigidity in gender roles makes no sense, and both men and women move towards the characteristics and functions that are considered typical of the other gender. At this time, the differences between genders start to diminish. This is what some authors (Livson 1983) call changes in the middle of the life cycle and which will become more marked between the ages of 50 and above. Taking these ideas as a base, and coinciding with other research work that has adopted this approach, this study has chosen to use each decade as an age category. From this perspective, the very make-up of each age group was taken into account with regard to characteristics such as having children or not, and the children's age. In this sense, as the participants' age increased, so did the probability of having children and the age of these children. So, in age group 1 there are 
no participants with children; in group 2, 57.33\% has children and shows the highest percentage of children underthe ageof 6; in group 3, 73\% has children and shows the highest percentage of children aged between 13 and18; in group 4, all the participants have children,butthey have the highest percentage of children over the age of 19 .

The gender role orientation was assessed using the BSRI (Bem Sex Role Inventory, 1974). This inventory assesses the degree to which a person describes him or herself in terms of positive expressive and instrumental attributes that are considered to be socially desirable for men and women, respectively. The relative questionnaire is selfadministered and is made up of 60 personality characteristics or attributes, of which 20 form a scale of masculinity (for example: independent, dominant, ambitious); 20 form a femininity scale (yielding, affectionate, sensitive to others' needs); and 20 form a scale of social desirability or attrbutes that are neutral as regards gender (helpful, moody, happy). This study has used a version that has been translated into Spanish by experts and its theoretical and empirical bases have been analysed according to the gender models indicated by Bem (1974), (Fernández 1983 and Vergara 1993). The response format is based on a Likert-type scale ranging from 1 (never or almost never) to 7 (always or almost always). Our study obtained an Alpha coefficient of 0.85 for the masculinity dimension, and .76 for the femininity dimension. The social desirability average, once the scores of negative items had been inverted, was 5.17 ( $\mathrm{SD}=.535)$. According to Bem, these neutral items should be equally desirable for men and for women alike. The results of the analysis, $t$ tests, revealed no significant gender differences as regards social desirability $(\mathrm{t}=-1.21 ; \mathrm{p}=.228$; men: $\mathrm{x} 1 / 45$ 5:12; $\mathrm{SD}=.57$; women: $\mathrm{x}^{1 / 45}$ :23; $\mathrm{SD}=.48$ ). The $\mathrm{BSRI}$ has been conceptually and methodologically criticised (Marsch et al. 1989; Spence 1991). However, many authors point out that, at this moment in time, this inventory operationalises the characteristics of femininity and masculinity better than any other. To this effect, it is worth pointing out that it is the most frequently used inventory in gender-related research, it has been used in over 1,000 ERIC articles and documents (Beere 1990) and used in many transcultural studies, which reveal that there is general agreement in the description of what is understood by masculinity and femininity. 


\section{Procedure}

In order to obtain the participants in this study, questionnaires were distributed in different centres or faculties forming part of the University of Granada, covering all the existing specialities and fields (sciences, humanities, art, etc.). We should mention here that both jobs are mainly held by males. However, in order to obtain a comparable number of men and women for each job, the same percentage of questionnaires was handed out to men and women. The questionnaires were administered individually to each worker. Participation was voluntary and anonymous. After requesting their collaboration, they were given the questionnaire and, even though it had specific instructions attached, they were explained the correct way to complete the survey. Given that the questionnaires were distributed during working hours, they were given a week to fill them in. 220 questionnaires were handed out. 164 were filled in, but only 137 of them were considered for the study as they were the only ones that had been completed in full.

\section{Results}

\section{Preliminary Analyses}

Table 1 shows the average scores obtained in masculinity and femininity according to gender, age and level of education. The results of a MANOVA analysis in which gender, ageand level of education were considered as independent variables, and masculinity and femininity as dependent variables, indicated the existence of significant differences according togender in masculinity $[F(1,121)=15.320 ; p=.001]$ and in femininity $[\mathrm{F}(1,121)=4.115 ; \mathrm{p}=.045]$, and according to level of education in femininity [F $(1,121)=4.942 ; p=.028]$. Likewise, significant differences were obtained according to the effects of the interaction between gender and the level of education in femininity $[F(1,121)=4.238 ; p=.042]$ and the differences obtained according to the effects of the interaction of gender and age in masculinity were close to significant $[\mathrm{F}(3,121)=2.458$; $\mathrm{p}=.066]$. 
Table 1 Means Scores in masculinity and feminity according to gender, age and level of education.

\begin{tabular}{|c|c|c|c|c|c|}
\hline & & \multicolumn{2}{|l|}{ Means } & \multicolumn{2}{|l|}{ SD } \\
\hline & & Masculinity & Feminity & Masculinity & Feminity \\
\hline \multirow[t]{2}{*}{ Gender } & Men & 4.835 & 4.741 & .719 & .524 \\
\hline & Women & 4.282 & 4.900 & .765 & .595 \\
\hline \multirow[t]{4}{*}{ Age } & Group 1 & 4.269 & 4.984 & .837 & .443 \\
\hline & Group 2 & 4.486 & 4.688 & .831 & .534 \\
\hline & Group 3 & 4.820 & 4.933 & .574 & .542 \\
\hline & Group 4 & 4.855 & 5.058 & .749 & .660 \\
\hline \multirow[t]{2}{*}{ Level of Education } & Low & 4.734 & 5.061 & .868 & .620 \\
\hline & High & 4.526 & 4.727 & .754 & .514 \\
\hline
\end{tabular}

Endpoints range from 1 (never or almost never) to 7 (always or almost always)

\section{Primary Analyses}

\section{Hypothesis 1}

Women will be more feminine than men and men will be more masculine than women. The results obtained in the aforementioned MANOVA indicated that therewere differences between men and women in masculinity and femininity. Men are more

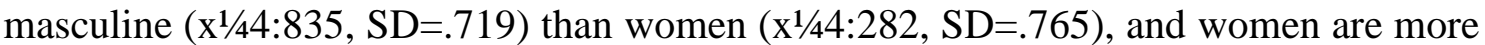
feminine $\left(x^{1 / 44}: 900, S D=.595\right)$ than men $\left(x^{1 / 4} 4: 741, S D=.524\right)$. It is worth pointing out that, while the differences obtained in masculinity were significant at a confidence level of $\mathrm{p}<.01$, those obtained in femininity were significant at a confidence level of $\mathrm{p}<.05$.

\section{Hypothesis 2}

There will be differences between genders in masculinity and femininity when both genders are aged between 30 and 39: men will be more masculine and women will be more feminine. In order to verify this hypothesis, analyses of mean difference, $t$ tests, were carried out, for each age group. Gender was taken as the independent variable and masculinity and femininity were taken as the dependent variables. The results indicated that there were significant differences in masculinity in age group 1 (from the age of 20 to 29) and in age group 2 (from 30 to 39 ; see Table 2).

Men in both these age groups are more masculine (Group 1: $\mathrm{x}^{1 / 44}: 950 ; \mathrm{SD}=.295$; Group 2: $\mathrm{x}^{1 / 4} 4$ 4:796; $\mathrm{SD}=.8034$ ) than women in both age groups (Group 1: $\mathrm{x}^{1 / 4} \mathbf{4} 3: 843 ; \mathrm{SD}=.783$; Group 2: $\left.x_{1}^{1 / 44: 113 ;} \mathrm{SD}=.7099\right)$. No significant differences were found between genders in masculinity in the other age groups (from the age of 40 to 50 and from 50 to 64). 
Neither were significant differences found between genders regarding femininity in any age group (see Table 2).

\section{Hypothesis 3}

Women aged between 30 and 39 will be more feminine than women in all the other age groups; likewise, men aged between 30 and 39 will be more masculine than men in all the other age groups.

\section{Hypothesis 4}

Women aged between 50 and 64 will be more masculine than women in all the other age groups; likewise, men aged between 50 and 64 will be more feminine than men in all the other age groups. To verify this hypothesis, analyses of variance were carried out for each gender. Age was taken as the independent variable in each analysis, and masculinity and femininity were taken as dependent variables. The results indicated that there were no significant differences between men according to age, neither in masculinity $[\mathrm{F}(3,69)=.194 ; \mathrm{p}=.900]$ nor femininity $[\mathrm{F}(3,69)=.599 ; \mathrm{p}=.618]$. However, when women from the different age groups were compared, significant differences were shown in both masculinity $[\mathrm{F}(3,59)=4.439 ; \mathrm{p}=.007]$ and femininity $[\mathrm{F}(3,59)=3.673$; $\mathrm{p}=.017]$. The multiple comparisons made using the Schefe test revealed that the differences obtained were only close to the generally accepted significance level of $\mathrm{p}<.05$. Women in group 3 (aged 40 to 49; differences of $x^{1 / 4}: 829 ; p=.091$ ) and women in group 4 (aged 50 to 64; Differences of $x^{1 / 4}: 962 ; p=.072$ ) are more masculine than women in group 1 (aged 20 to 29). Likewise, women in group 4 (aged 50 to 64) are more feminine than women in group 2 (aged 30 to 39; differences of $x^{1 / 4}: 632 ; p=.050$ ). Table 3 shows the averages obtained for men and women regarding masculinity and femininity in the different age groups. 
Table 2 Statistics of the analysis of mean differences between genders according to age and level of education.

\begin{tabular}{lllll}
\hline Dimensions & Variables & $t$ & $d f$ & $p$ \\
\hline Masculinity & Group 1 (20-29 age) & $2.984 *$ & 11 & .012 \\
& Group 2 (30-39 age) & $3.862 * *$ & 73 & .001 \\
& Group 3 (40-49 age) & 1.236 & 28 & .227 \\
& Group 4 (50-59 age) & .243 & 16 & .811 \\
Feminity & Group 1 (20-29 age) & -.400 & 11 & .697 \\
& Group 2 (30-39 age) & -.154 & 73 & .878 \\
& Group 3 (40-49 age) & -1.393 & 28 & .175 \\
& Group 4 (50-59 age) & -1.643 & 16 & .120 \\
Masculinity & Low Level of Education & $2.508 *$ & 34 & .017 \\
& High Level of Education & $3.532 * *$ & 99 & .001 \\
Feminity & Low Level of Education & $-2.611 *$ & 34 & .013 \\
& High Level of Education & -.433 & 99 & .666 \\
\hline$* p<.05$ & & & & \\
$* * p<.01$ & & & &
\end{tabular}

Table 3 Statistics of the analysis of mean differences within each gender according to the age.

\begin{tabular}{lllll}
\hline Gender & Dimensions & Group of age & Mean & SD \\
\hline Men & \multirow{2}{*}{ Masculinity } & Group 1 (20-29) & 4.950 & .295 \\
& & Group 2 (30-39) & 4.796 & .803 \\
& & Group 3 (40-49) & 4.932 & .661 \\
& \multirow{4}{*}{ Feminity } & Group 4 (50-64) & 4.895 & .564 \\
& & Group 1 (20-29) & 4.920 & .323 \\
\multirow{4}{*}{ Women } & Group 2 (30-39) & 4.679 & .515 \\
& \multirow{4}{*}{ Masculinity } & Group 3 (40-49) & 4.814 & .539 \\
& & Group 4 (50-64) & 4.840 & .626 \\
& & Group 1 (20-29) & 3.843 & .783 \\
& & Group 2 (30-39) & 4.113 & .709 \\
& Feminity & Group 3 (40-49) & 4.673 & .416 \\
& & Group 4 (50-64) & 4.806 & .973 \\
& & Group 1 (20-29) & 5.025 & .522 \\
& & Group 2 (30-39) & 4.698 & .562 \\
& & Group 3 (40-49) & 5.088 & .524 \\
& & Group 4 (50-64) & 5.331 & .635 \\
\hline
\end{tabular}

Endpoints range from 1 (never or almost never) to 7 (always or almost always)

\section{Hypothesis 5}

Therewillbedifferencesbetweengendersinmasculinityand femininity when the level of education is low: men will be more masculine and women will be more feminine. In order to verify this hypothesis, analyses of mean difference, $t$ tests, were carried out, for each particular level of education group. Gender was taken as the independent variable and masculinity and femininity were taken as the dependent variables. The results obtained revealed that there were significant differences in masculinity and femininity 
between men and women with a low level of education (see Table 2), such that women were more feminine $\left(\mathrm{x}^{1} / 45: 340 ; \mathrm{SD}=.567\right)$, than men $\left(\mathrm{x}^{1} / 44: 837 ; \mathrm{SD}=.580\right)$, and that men were more masculine $\left(x^{1 / 4} 5: 037 ; S D=.678\right)$, than women $\left(x^{1 / 44}: 356 ; S D=.950\right)$. When the level of education is high, we found significant differences between genders in masculinity, such that men were more masculine $\left(x^{1 / 4} 4: 761 ; S D=.725\right)$ than women $\left(x^{1 / 4}\right.$ $4: 257 ; \mathrm{SD}=.702)$. No significant differences were obtained with regard to femininity.

\section{Hypothesis 6}

Women with a lower level of education will be more feminine than women with a higher level of education; likewise, men with a lower level of education will be more masculine than those with a higher level of education. To verify this Hypothesis analyses of mean difference, $\mathrm{t}$ tests, were carried out, for each gender. Level of education were taken as independent variable in each analysis, and masculinity and femininity were taken as dependent variables. The results indicated that there were no significant differences between men with a high or low level of education, neither in masculinity nor femininity (see Table 4). With regard to the women, there were also no apparent differences in masculinity, although there were differences in femininity, with women with a lower level of education $\left(\mathrm{x}^{1 / 45} / 340 ; \mathrm{SD}=.567\right)$ being more feminine than

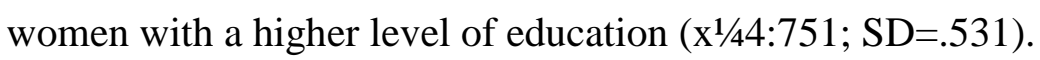

Table 4 Statistics of the analysis of mean differences within each gender according to level of education.

\begin{tabular}{lllrrr}
\hline & \multirow{2}{*}{ Gender } & Dimensions & \multicolumn{1}{l}{$t$} & $d f$ & \multicolumn{1}{c}{$p$} \\
\hline Level of Education & \multirow{2}{*}{ Men } & Masculinity & 1.480 & 72 & .143 \\
& & Feminity & .954 & 72 & .343 \\
& \multirow{2}{*}{ Women } & Masculinity & .443 & 61 & .659 \\
& & Feminity & $3.770^{*}$ & 61 & .001
\end{tabular}

$* p<.01$ 


\section{Discussion}

This study's first objective was to verify the extent to which men and women adopt traditional gender role orientations. To this effect, the following hypothesis was set:

\section{Hypothesis 1}

Women will be more feminine than men and men will be more masculine than women. The results support this hypothesis, as men obtain a higher score in masculinity than women and the latter score higher in femininity than men. The results are consistent with those obtained in other studies (Ashmore 1990; Blanchard-Fields et al. 1997; Clekis 2000; Echevarría and Valencia 1993; Marsh and Myers 1986; Spence and Buckner 2000; Twenge 1997b). However, the differences found in femininity $(p<.045)$ are less marked than those of masculinity $(\mathrm{p}<.001)$. This lesser degree of differences between genders as regards femininity may be due to the effect of the participants' occupations (university teaching staff and janitors), as these occupations are mainly maledominated, and, as certain studies have pointed out, in these types of occupations there is a tendency to obtain low scores in femininity (Echevarría and Valencia 1993; Sowles 2004). For that reason, it is possible that women adhere less to feminine traits, which would lead to the differences being less marked. Furthermore, Hofstede (1998) hypothesises that the gender differences in stereotypes and gender roles may be less marked in societies that are low in masculinity or more feminine. Given that, in comparison with other countries, Spain obtains a low rate of masculinity in his studies, consequently proving to be a more feminine country, the results could be reflecting the effects of Spanish culture. The second objective aimed to verify whether age and level of education determined differences in gender role orientation, both when comparing between the two genders and when the comparisons are made within the same gender. With regard to this objective, several hypotheses were set.

\section{Differences Between Genders According to Age: Hypothesis 2}

\section{Hypothesis 2}

There will be differences between genders in masculinity and femininity when both genders are aged between 30 and 39: men will be more masculine and women will be more feminine. The results obtained partially support hypothesis 2 . There were significant differences in masculinity in age groups 1 (aged 20-29) and 2 (30-39), such 
that men were more masculine than women. No significant differences were found between the two genders in age groups $3(40-49)$ and 4 (50-64). This supports the predictions established with regard to masculinity. However, this is not the case for femininity, as no differences were found between genders regarding femininity in any age group. While the results for masculinity are in line with the idea that men are more attached to masculine characteristics than women in younger ages and/or early adulthood, the results for femininity do not show that women are more attached to feminine characteristics than men at these ages (Feldman et al. 1981; Gutmann 1975, 1977; Livson 1983). Furthermore, the fact that there were no apparent gender differences in either of the two dimensions from age groups 3 (40-49) and 4 (50-64) supports the notion that, at these ages, gender differences in masculinity and femininity tend to disappear (Feldman et al. 1981; Gutmann 1975, 1977; Livson 1983). Besides, these results tend to appear on the same line as those obtained in other studies which reveal that masculinity is higher in women between the ages of 43 and 52 (Kasen et al. 2006; Parker and Aldwin 1997).

\section{Differences Within each Gender According to Age: Hypotheses 3 and 4}

\section{Hypothesis 3}

Women aged between 30 and 39 will be more feminine than women in all the other age groups; likewise, men aged between 30 and 39 will be more masculine than men in all the other age groups.

\section{Hypothesis 4}

Women aged between 50 and 64 will be more masculine than women in all the other age groups; likewise, men aged between 50 and 64 will be more feminine than men in all the other age groups. Theresultsshowedthattherewerenodifferencesbetween men, neither in masculinity nor femininity, in the different age groups, with both scores remaining relatively constant acrosstheagerange.Therefore, theresultsdonotsupportthe predictions established for men in hypotheses 3 and 4, so there is no confirmation that men adhere more strongly to masculinity traits in the early adulthood stage (Gutmann 1975, 1977; Levinson et al. 1978; Livson 1983) and there is also no confirmation that men adhere more strongly to feminine traits around the middle of the life cycle, contrary to the results obtained in other studies (Fischer and Narus 1981; Heilbrun 1981; Mandel 
1987; Sinnott 1984). However, in women, the results of variance analysis indicated significant differences in masculinity between the different age groups. The means scores suggest as they got older, their adherence to masculine characteristics increased. Although the results of the Schefe test revealed no differences at the 5\% significance level for masculinity, the differences that were relatively close to the significance level indicated that women in age groups $3(40-49)$ and 4 (50-64) were more masculine than those in group 1 (20-29). So these results tend to support hypothesis 4, at least where women's masculinity is concerned. These results are in line with those obtained in other studies which point out that masculinity is higher in women between the ages of 40 and 50 (Helson and Wink 1992; Kasen et al. 2006; Parker and Aldwin 1997). Regarding femininity, the results of the variance analysis and the Schefe test showed that women in age group 4 (50-64) were significantly more feminine than those in group 2 (30-39). These results do not confirm the predictions of hypothesis 3 regarding femininity in women. The fact that women in age group 2 (aged 30-39) score lower in femininity in comparison with those in age group 4 (50-64) contradicts the idea that women are particularly more feminine at those ages in which they take on parental responsibilities (Gutmann 1975, 1977). In this sense, it is worth mentioning that in our study, the participants in this age group (aged 30-39) had a higher percentage of children under the age of 6 than the other groups, so our results seem to support those obtained in other studies which conclude that, at least in the case of women, changes in femininity (and masculinity) are not associated with family roles (Abele 2003; McHale and Huston 1984), or that femininity decreases with the presence of children in the home, rather like an automatic mechanism for coping with the significant psychological stress and overloading of the role they have to fulfil (Kasen et al. 2006). Furthermore, the fact that women in age group 4 (50-64) scored highest in femininity is in line with the results obtained in other studies which have shown that femininity increases between the ages of 40 and 50 (Stewart et al.2001) or between the ages of 39 and 59 (Kasen et al. 2006).

\section{Differences Between Genders According to Level of Education: Hypothesis 5}

\section{Hypothesis 5}

There will be differences between genders in masculinity and femininity when the level of education is low: men will be more masculine and women will be more feminine. The results showed that, when men and women with a low level of education were 
compared, men were more masculine than women, and that women were more feminine than men. However, when men and women with a high level of education were compared, men were more masculine than women, but women were not more feminine than men. These results suggest that when the level of education is low, men and women adhere more to traditional gender role orientations than when the level of education is high, confirming the predictions set in hypothesis 5 for a low level of education.

\section{Differences Within each Gender According to Level of Education: Hypothesis 6}

\section{Hypothesis 6}

Women with a lower level of education will be more feminine than women with a higher level of education; likewise, men with a lower level of education will be more masculine than those with a higher level of education. The results showed that the level of education predicted differences in femininity among women, but not among men. Women with a lower level of education were shown to be more feminine than those with a higher level of education. Consequently, the predictions set in hypothesis 6 are confirmed for women, but not for men. These results are in line with those obtained in other studies (Abele 2000, 2003; Cunningham and Antill 1984; Kasen et al. 2006; Twenge 2001), and support the assumption that women with a low level of education tend to share the traditional gender role socialisation to a greater extent than those with a higher level of education. However, there were no differences between women with a high and low level of education regarding masculinity, which contradicts the results of other studies where professional women or those with a high level of education were shown to have a tendency for a high degree of masculine characteristics (Abele 2000, 2003; Cunningham and Antill 1984; Holahan and Gilbert 1979; Kasen et al. 2006; Spence and Helmreich 1978; Twenge 2001). Perhaps the fact that women from both educational levels hold down mainly male-dominated jobs could mean that the effects of the level of education take a secondary position to the effects that the type of job they do may impose. In this sense, some studies have pointed out that performing typically masculine occupations affects men and women's gender role orientation, such that they tend to adopt an essentially masculine, followed by undifferentiated, orientation (Echevarría and Valencia 1993; Sowles 2004). In short, the results of this study support Hypothesis 1, as men are indeed more masculine than women, and women are more 
feminine than men. They also partially support the hypotheses set for the differences between genders (Hypotheses 2 and 5), as men are more masculine than women between the ages of 20 and 39, but women are not more feminine than men in that age group (Hypothesis 2). Likewise, there are no differences between genders neither in masculinity nor in femininity between the ages of 40 and 64. At lower levels of education, men are more masculine and women are more feminine, whereas at higher levels of education, men are more masculine than women, but women are not more feminine than men (Hypothesis 5). Furthermore, the results also partially support the hypotheses set for the differences within each gender (Hypotheses 3, 4 and 6). Thus, hypothesis 3 is not supported, as no significant differences were obtained in masculinity between men according to age, nor are women aged between 30 and 39 more feminine than women in the other age groups. Hypothesis 4 was partially supported, as women aged between 40 and 64 are more masculine than those aged between 20 and 39, but men between the ages of 40 and 64 are not more feminine than those aged 20 to 39 . Finally, hypothesis 6 was only partially supported, as women with a low level of education are more feminine than those with a high level of education, but men with a low level of education were not more masculine than those with a high level of education.

\section{Conclusions}

To conclude, it could be said that the results of this study indicate that age and level of education determine differences in women's gender role orientation but not in men. In short, the age and the level of education are more important factors when it comes to explaining possible differences in gender role orientation in women than they are for the case of men. The pattern of results obtained suggests that the masculine stereotype has a more rigid configuration than its feminine counterpart. These results are consistent with those obtained in other research studies reflecting more differences between women than between men (Crompton et al. 2005; Hochschild 1990; Kulik 2002; Myer and Booth 2002; Twenge 1997a). Some studies suggest that, while women develop their gender ideology mainly out of their own adult experiences, adapting more easily to their situation and abilities, men essentially develop from the influences they receive in their family and home environment (Myer and Booth 2002). As Hochschild (1990) points out, it is possible that the rapid changes in job opportunities, and the evolution of society itself, all have a greater influence on women than on men, due to the fact that 
the traditional distribution of gender roles provides more advantages to men than to women. So, while women, for example, are offered a more structured, more restricted and more controlled environment, where novelties are less acknowledged, men are offered a much broader and less controlled world with more work and social opportunities, greater possibilities to discover things for themselves, to improvise and solve problems, to develop skills, they are awarded more authority and prestige, etc. Thus, it is possible that women may perceive material and cultural incentives that encourage them to adopt other attitudes and ideologies (Myer and Booth 2002), which remove them from the restrictions and disadvantages that are typical of traditional gender ideology. In this way they achieve a greater level of autonomy, independence, and possibilities to reach a higher personal level of enrichment and accomplishment, increased growth and, in short, a fuller life. Men, on the other hand, will probably perceive losses or disadvantages if they adopt non-traditional gender ideologies and attitudes. Furthermore, we must also bear in mind that traditional gender role socialisation emphasises the values that allow one to be successful in the work environment. So, some studies have found a clear association between working in traditionally masculine occupations and the development of a masculine gender role orientation, the internalisation of socio-occupational achievement values and belonging to the male sex group (Echevarría 1993). Moreover, given that some studies have indicated that in mostly male-dominated occupations, the adoption of a feminine gender role orientation predicts a higher degree of gender role conflict and that the adoption of a masculine gender role orientation predicts a lower degree of conflict (Luhaorg and Zivian 1995), it is possible that the lack of differences between the men in both dimensions is due to a need, on one hand, to be successful in their profession, and on the other hand, to reduce the experience of conflict.

In general, researchers who have analysed gender differences have focused on comparing all men with all women, assuming that all men and women are the same, or that they all share in the rational gender roles, stereotypes and expectations to the same degree. The results are subsequently interpreted from a gender role socialisation viewpoint, taking gender itself as a factor explaining said differences, in the understanding that the mere fact of being a man or a woman largely reflects the stereotypes and expectations inherent in the masculine and feminine gender role socialisation that they have internalised. However, and as can be seen in the results of 
this study, there are reasons to believe that not all men nor all women are alike and that there are individual differences, both between genders and within each gender, regarding gender role orientation. If the degree to which both genders adopt traditional gender roles may vary, gender by itself may not necessarily explain the attributes, qualities and skills associated with gender role socialisation, and consequently, it may not be the best predictor of differences. For this reason, we believe that gender differences should be analysed from the viewpoint of the possible individual differences that may arise between genders and within each gender, with regard to the degree of internalisation of traditional gender roles. This analysis would enable us to interpret the gender differences found, for example, in attitudes and behaviour related to work and family, in the light of the individual differences in gender role socialisation. Lastly, we would like to point out some of this study's limitations, which mean that our results cannot be generalised. For example, the sample used must be taken into account. This was made up of workers from two jobs in one single organisation. Likewise, the two jobs in question are largely male-dominated. For that reason, the consequences implied by these results must be limited to the analysed sample. It would also be necessary to identify the factors that could enable us to discover the individual differences in gender role orientation, such as religion, race, socioeconomic status, type of occupation, whether the subject comes from a family where the father and mother work, etc. Likewise, it would be necessary to improve the gender role orientation measurements and carry out studies which simultaneously consider different indicators or measurements on the degree of internalisation of traditional gender roles and expectations. Current gender role orientation measurements mainly focus on assessing personality traits that covary with gender. However, the identity or selfconcept of gender is not only made up of personality traits, so it would be useful to develop assessment instruments that take on other aspects of gender identity, such as activities, attitudes, preferences, interests, roles, etc. 


\section{References}

Abele, A. (2000). A dual impact model of gender and career related processes. In T. Eckes \& H. M. Trautner (Eds.), The develop- mental social psychology of gender (pp. 361-388). Hillsdale, NJ: Erlbaum.

Abele, A. (2003). The dynamics of masculine-agentic and feminine- communal traits: Findings from a prospective study. Journal of Personality and Social Psychology, $85,768-776$.

Agut, S., \& Salanova, M. (1997). Mujer y trabajo. Un reto para la investigación psicosocial. (Woman and work. A challenge for the psychosocial research). IV Congress of Social Psychology: Integration and Development of the Social Psychology in a Multicultural Society. San Sebastián.

Ashmore, R. D. (1990). Sex, gender, and the individual. In L. A. Pervin (Ed.), Handbook of personality: Theory and research (pp. 486-526). New York: Guilford Press.

Auster, C. \& Ohm, S. (2000). Masculinity and feminity in contem- porary American society: A reevaluation using the Bem Sex-Role Inventory. Sex Roles, 43, 499-528.

Beere, C. (1990). Gender roles. A handbook of tests and measures. New York: Greenwood Press.

Bem, S. (1974). The measurement of psychological androgyny. Journal of Consulting and Clinical Psychology, 42, 155-162.

Bem, S. (1993). The lenses of gender: Transforming the debate on sexual inequality. New Haven, CT: Yale University Press.

Blanchard-Fields, F., Chen, Y., \& Hebert, C. E. (1997). Interrole conflict as a function of life stage, gender, and gender-related personality attributes. Sex Roles, 37, 155174.

Bonilla, A. (1998). Los roles de género. (The roles of gender). In J. Fernández (Coord.): Género y Sociedad, (Gender and Society) (pp. 141-176). Pirámide: Madrid.

Brewster, K., \& Padavic, I. (2000). Change in gender-ideology, 1977-1996: The contributions of intracohort change and population turnover. Journal of Marriage and the Family, 62, 477-487. 
Calvo, A. (2002). El significado del trabajo desde la perspectiva de las diferencias de sexo/género: modelo del trabajo, modelo del género y modelo integrado (The meaning of work from sex/ gender differences perspective: work model, gender model and integrated model). Tesis Doctoral. (Dissertation). Universidad de Granada.

Carvajal, F., Sebatián, J., Cornide, E., Delgado, A., Castellote, I., \& Blanco, C. (1990). Implicaciones del modelo de la androginia en el comportamiento sexual: arousal subjetivo y fantasías sexuales (Psychological androginy effects upon sexual behavior: subjective arousal and sexual fantasies). Revista de Psicología Social, 5, 23 42.

Cinamon, R., \& Rich, Y. (2002). Gender differences in the importance of work and family roles: Implications for work-family conflict. Sex Roles, 47, 531-542.

Clarey, J., \& Stanford, A. (1982). Female career preference and androgyny. Vocational Guidance Quarterly, 30, 258-264.

Clekis, J. (2000). The relationship between age, experience, and gender roles in veterinarians. Dissertation. University of Sar- asota, USA: Florida.

Crompton, R., Brockman, M., \& Lyonette, C. (2005). Attitudes, women's employment and the domestic division of labour: A cross-national analysis in two waves. Work, Employment and Society, 19, 213-233.

Cunningham, J., \& Antill, J. (1984). Changes in Masculinity and Feminity across the family life cycle: A reexamination. Developmental Psychology, 20, 1135-1141.

Duxbury, L., \& Higgins, C. (1991). Gender differences in work-family conflict. Journal of Applied Psychology, 76, 60-74.

Echevarría, A. (1993). Gender social identity, values and cognitive styles. Revue Internationale de Psychologie Sociale, 5, 2.

Echevarría, A., \& Valencia, J. (1993). Gender identity, protestant work ethic and the attribution of causality. Revista de Psicología Social, 8, 235-247.

Echevarría, A., Valencia, J., Ibarbia, C., \& García, L. (1992). Identidad social y de género, evaluaciones intercategoriales y percepción social (Social and gender identity, intercategorial evaluations and social perception). Revista de Psicología Social, 8, 235-247.

Feldman, S., Biringen, Z., \& Nash, S. (1981). Fluctuations of sex- related selfattibutions as a function of stage of family life cycle. Developmental Psychology, $17,24-35$. 
Fernández, J. (1983). Nuevas perspectivas en la medida de masculin- idad y feminidad (New perspectives in the masculinity and femininity measure). Madrid: Editorial de la Universidad Complutense de Madrid.

Fernández, J. (1988). Nuevas perspectivas en el desarrollo de sexo y del género (New perspectives in the sex and gender development). Madrid: Pirámide.

Fischer, L., \& Narus, L. (1981). Sex-Role Development in late Adolescence and Adulthood. Sex Roles, 7, 97-106.

García-Mina, A. (2002). La influencia de la edad en la percepción de los estereotipos de rol de género (The age influence in the gender role stereotypes perception). In P. Pérez \& M. Ortega (Eds.), Las edades de las mujeres. (The ages of women) (pp. 421-441). Instituto Universitario de Estudios de la Mujer. Universidad Autónoma de Madrid.

García-Vega, E., Fernández, P., \& Rico, R. (2005). Género y sexo como variables moduladoras del comportamiento sexual en jóvenes universitarios (Gender and sex as moderator variables of the sexual behaviour in young university students). Psicothema, 17, 49-56.

Gutek, B. A., Searle, S., \& Klepa, L. (1991). Racional versus gender role explanations for work-family conflict. Journal of Applied Psychology, 76(4), 560-568.

Gutmann, D. (1975). Parenthood: Key to the comparative psychology of life? In N. Datan \& L. Ginsberg (Eds.), Life -span developmental psychology: Normative life crises (pp. 98-119). San Diego, CA: Academic.

Gutmann, D. (1977). The cros-cultural perspective: Notes towards a comparative psychology of aging. In J. Birren \& K. Schaie (Eds.), Handbook on the psychology of aging. Nueva York: Van Nostrand Reinhold.

Heilbrun, A. (1981). Gender differences in the functional linkage between androgyny, social cognition, and competence. Journal of Personality and Social Psychology, $41,1106-1118$.

Helson, R., Jones, C., \& Kwan, V. (2002). Personality change over 40 years of adulthood: Hierarchical linear modeling analices of two longitudinal simples. Journal of Personality and Social Psychology, 83, 752-766.

Helson, R., \& Moane, G. (1987). Personality change in women from college to midlife. Journal of Personality and Social Psychology, 53, 176-186.

Helson, R., \& Wink, P. (1992). Personality change in woman from the early 40s to 
early 50s. Psychology and Aging, 7, 46-55.

Hochschild, A. (1990). The secon shift. London: Piatkus.

Hofstede, G. (1998). Masculinity and feminity: The taboo dimension of national cultures. Thousand Oaks, CA: Sage.

Holahan, C., \& Gilbert, L. (1979). Interrole conflict for working women: Careers versus jobs. Journal of Applied Psychology, 64, 86-90.

Kane, E. (1995). Education and beliefs about gender inequality. Social Problems, 42, 74-90.

Kasen, S., Chen, H., Sneed, J., Crawford, T., \& Cohen, P. (2006). Social role and birth cohort influences on gender-linked personality traits in women: A 20-year longitudinal analysis. Journal of Personality and Social Psychology, 91, 944-958.

Kerpelman, J., \& Schvaneveldt, P. (1999). Young adults' anticipated identity importance of career, marital, and parental roles: Comparisons of men and women with different role balance orientation. Sex Roles, 42, 189-217.

Konrad, A., Ritchie, E., Lieb, P., \& Corrigall, E. (2000). Sex differences and similarities in job attribute prefernces: A meta- analysis. Psychological Bulletin, $126,593-641$.

Kulik, L. (2002). The impact of social background on gender-role ideology. Journal of Family Issues, 23, 53-73.

Levinson, D., Darrow, C., Klein, E., Levinson, M., \& McKee, B. (1978). The seasons of a man's life. New Cork: Knopf Books.

Livson, F. (1983). Gender identity: A life span view of sex-role development. In B. Ruth (Ed.), Sexuality in the later years. Nueva York: Academic.

López, F. (1988). Adquisición y desarrollo de la identidad sexual y de género (Sexual and gender identity: acquisition and development). In J. Fernández (Coord.): Nuevas perspectivas en el desarrollo de sexo y del género (New perspectives in the sex and gender development) (pp. 71-87). Madrid: Pirámide.

López-Zafra, E., \& López-Sáez, M. (2001). Por qué las mujeres se consideran más o menos femeninas y los hombres más o menos masculinos. Explicaciones sobre su autoconcepto de identidad de género. (Why women feel (more or less) feminine and men (more or less) masculine. Explanations offered for their self-concept of gender identity). Revista de Psicología Social, 16, 193-207. 
Lorenci-Cioldi, F. (1988). Individus dominants et groupes dominés. Images masculines femenines (Dominant individuals and domi- nated groups. Masculine and feminine images). Grenoble: Presses Universitaries de Grenoble.

Luhaorg, H., \& Zivian, M. T. (1995). Gender role confflict The interaction of gender, gender role, and occupation. Sex Roles, 33, 9-10, Nov.

Mandel, H. (1987). A comparison of differences in gender identity and sex-role adoption between males and females younger than 25 and older than 60 . Disertation, Developmental Psychology. Pacific Graduate School of Psychology, United States-California.

Marsch, H., Antill, J., \& Cunningham, J. (1989). Masculinity and feminity: A bipolar construct and independent constructs. Journal of Personality, 57, 625-663.

Marsden, P., Kalleberg, A., \& Cook, C. (1993). Gender differences in organizational commitment: Influences of work positions and family roles. Work and Occupations, 20, 368-390.

Marsh, H., \& Myers, M. (1986). Masculinity, feminity, and androyny: A methodological and theoretical critique. Sex Roles, 14, 397-430.

Martins-Crane, M., Beyerlein, M., \& Johson, D. (1995). Adjusting models of gender and work to new work enviroments. A Special Issue of the Journal of Social Behavior and Personality, 10, 27-49.

Matsumoto, D. (1996). Cultura and psychology. Pacific Grove: Brooks/Cole.

McHale, S., \& Huston, T. (1984). Men and women as parents: Sex role orientations, employment and parental roles with infants. Child development, 55, 1349-1361.

Moen, P., Erickson, M., \& Dempster-McClain, D. (1997). Their mother's daughters? The intergenerational transmission of gender attitudes in a world of changing roles. Journal of Marriage and the Family, 59, 281-293.

Myer, S., \& Both, A. (2002). Forerunners of cahange in nontraditional gender ideology. Social Psychology Quarterly, 65, 18-37.

Orwoll, L., \& Achenbaum, W. (1993). Gender and the development of wisdom. Human Development, 36, 274-296.

Parker, R., \& Aldwin, C. (1997). Do aspects of gemder identity change from early to middle adulthood? Disentangling age, cohort, and period effects. In M. Lachman \& J. James (Eds.), Multiple paths of middlife development (pp. 67-107). Chicago: University of Chicago Press. 
Pastor, R. (1998). Asimetría genérica y representaciones del género (Generic asymmetry and gender representations). In J. Fernández (Coord.): Género y Sociedad (Gender and Society), (pp. 207-235). Pirámide: Madrid.

Pastor, R., \& Martínez-Benlloch, I. (1991). Roles de género: Aspectos psicológicos de las relaciones entre los sexos (Gender roles: psychological aspects of the intersexes relationships). Investiga- ciones Psicológicas, 9, 117-143.

Poal, G. (1993). Entrar, quedarse y avanzar: aspectos psicosociales de la relación mujer-mundo laboral (To enter, to stay and to advance: psychosocial aspects of the woman-labor world relationship). México: Siglo XXI.

Ritzer, G. (1972). Man and his work: Conflict and change, Engle- wood Cliffs, NJ: Prentice-Hall.

Roberts, B. (1997). Plaster or plasticity: Are adult work experiences associated with personality change in women? Journal of Personality, 65, 205-232.

Roberts, B., Helson, R., \& Klohnen, E. (2002). Personality develop- ment and growth in women across 30 years: Three perspectives. Journal of Personality, 70, 79102.

Sinnott, J. (1984). Older men, older women: Are their perceived sex roles similar? Sex Roles, 10, 847-856.

Sowles, C. (2004). Adult development of women: Changes and constancy in the gender-role orientation of homemakers, women in female-dominated, and male dominated-professions. Disserta- tion Abstracts International: Section B: The Sciences and Engineerin, 64, 5235.

Spence, J. (1991). Do the BSRI and the PAQ measure the same or diffrent concepts? Psychology of Women Quarterly, 15, 141-165.

Spence, J., \& Buckner, C. (2000). Instrumental and expressive traits, trait stereotypes, and sexist attitudes. Psychology of Women Quarterly, 24, 44-62.

Spence, J., \& Helmreich, R. (1978). Masculinity and feminity: Their psychological dimensions, correlates, and antecedents. Austin: University of Texas Press.

Stewart, A., Ostrove, J., \& Helson, R. (2001). Middle aging in women: Patterns of personality change from the $30 \mathrm{~s}$ to the 50 s. Journal of Adult Development, 8, 2337.

Strange, C., \& Ria, J. (1983). Career choice considerations and sex role self-concept of male and female undergraduates in nontraditional majors. Journal of Vocational Beharvior, 23, 219-226. 
Togeby, L. (1995). Feminist attitudes: Social interests or political ideology. Women and Politics, 15, 39-61.

Turner, B., \& Turner, C. (1991). Bem Sex -Role Inventory stereotypes for men and women varying in age and race among national register psychologists. Psychological Reports, 69, 931-944.

Twenge, J. (1997a). Attitudes toward women, 1970-1995: A meta- analysis. Psychology of Women Quarterly, 21, 35-51.

Twenge, J. (1997b). Changes in masculine and feminine traits over time: A metaanalysis. Sex Roles, 36, 305-325.

Twenge, J. (2001). Changes in women's assertiveness in response to status and roles: A cross-temporal meta-analysis. Journal of Personality and Social Psychology, 81, $133-145$.

Tyer, Z., \& Erdwins, C. (1979). Relationship of sex role to male and female dominated proffessions. Psychologycal Reports, 44, 1134.

Unger, R. (1990). Los reflejos imperfectos de la realidad: la psicología construye los roles sexuales (The imperfect reflections of the reality: The psychology builds the sexual roles). In R. Hare- Mustin \& J. Marecek (Eds.), Marcar la diferencia: Psicología y construcción de los sexos (To mark the difference: Psychology and construction of the sexes). Barcelona: Herder.

Unger, R., \& Crawford, M. (1996). Women and gender: A feminist psychology. Nueva York: McGrraw-Hill.

Vandewater, E., \& Stewar, A. (1998). Making commitments, creating lives: Liking women's roles and personality at midlife. Psychol- ogy of Women Quarterly, 22, $717-738$.

Vaus, D., \& McAllister, I. (1991). Gender and work orientation. Work and Occupations, 18, 72-93.

Vedovato, S., \& Vaughter, R. (1980). Psychology of women courses changing sexist and sex-typed attitudes. Psychology of Women Quarterly, 4, 587-590.

Vergara, A. (1993). Sexo e identidad de género: Diferencias en el conocimiento social de las emociones y en el modo de compartirlas (Sex and identity of gender: Differences in the social knowledge of the emotions and in the way of sharing them). Tesis Doctoral (Disertation). Universidad del País Vasco. 
Wood, W., \& Eagly, A. (2002). A cross-cultural analysis of the behavior of women and men: Implications for the origins of sex differences. Psychological Bulletin, 128, 699-727.

Yammarino, F., \& Dubinsky, A. (1988). Employee responses: Gender or job related differences? Journal of Vocational Behavior, 32, 366-383. 